\title{
High Pressure Thermal Inactivation Kinetics of a Plasmin System
}

\author{
D. Borda, ${ }^{1}$ Indrawati, ${ }^{2}$ C. Smout, ${ }^{2}$ A. Van Loey, ${ }^{2}$ and M. Hendrickx ${ }^{2}$ \\ ${ }^{1}$ Department of Food Bioengineering, Faculty of Food Science and Engineering, \\ University Dunarea de Jos, 800201, Galati, Romania \\ ${ }^{2}$ Laboratory of Food Technology, Department of Food and Microbial Technology, \\ Katholieke Universiteit Leuven, B-3001 Heverlee (Leuven), Belgium
}

\section{ABSTRACT}

A crude plasmin extract was prepared from milk by ultracentrifugation and was partially purified using ammonium sulfate precipitation. Isothermal and highpressure inactivation of this plasmin system at $\mathrm{pH} 6.7$ could be described by a first-order kinetic model. As expected, the plasmin system displayed a high thermostability. High-pressure treatments were conducted in the 300 - to $800-\mathrm{MPa}$ pressure range, combined with temperatures from 25 to $65^{\circ} \mathrm{C}$. The plasmin system was very pressure stable at room temperature, but inactivation occurred with combined high-pressure/temperature-treatments. The influence of temperature at different constant pressures on the inactivation rate constant was quantified using the Arrhenius equation. At all temperatures studied, a synergistic effect of temperature and high pressure was observed in the 300 - to 600 $\mathrm{MPa}$ pressure range. However, an antagonistic effect of temperature and pressure appeared at pressures above $600 \mathrm{MPa}$.

(Key words plasmin system, high pressure, temperature, inactivation)

Abbreviation key: PA = plasminogen activators, $\mathbf{P A I}=$ plasmin activator inhibitors, $\mathbf{P I}=$ plasmin inhibitors.

\section{INTRODUCTION}

Plasmin (EC 3.4.21.7), the main native protease in milk, is part of a complex system consisting of plasminogen, plasminogen activators (PA), plasminogen activator inhibitors (PAI), plasmin, and plasmin inhibitors (PI) (Crudden and Kelly, 2003). An important part of the potential plasmin activity is present as plasminogen. In fresh milk, the concentration of plasminogen is much higher than that of plasmin (Nielsen, 2003). The levels of plasmin and plasminogen can vary consider-

Received January 14, 2004.

Accepted April 29, 2004.

Corresponding author: D. Borda; e-mail: Daniela.Borda@ugal.ro. ably with the stage of lactation, breed, age, and presence of mastitis (Grufferty and Fox, 1986).

Many interactions between plasminogen, plasmin, PA, PAI, and PI characterize the plasmin system. The role of PA in the system is to mediate plasminogen conversion into plasmin, whereas PAI and PI inhibit PA and plasmin activities, respectively. Two major types of PA are known to be present in fresh milk: a tissue-type associated with casein and a urokinase type associated with the somatic cells. Plasmin inhibitors and PAI are located mainly in milk serum; however, the inhibitors might appear in several different forms, possibly due to formation of complexes with other milk proteins (Preceti et al., 1997). $\alpha_{1}$-Antitrypsin, $\alpha_{2}$-antiplasmin, and PAI have been isolated from milk serum and partially characterized (Weber and Nielsen, 1991).

Plasmin is an alkaline serine proteinase with $\mathrm{pH}$ optimum of 7.5, which readily hydrolyzes $\beta$-casein, $\alpha \mathrm{s}_{2}-$ casein, and (more slowly) $\alpha \mathrm{s}_{1}$-casein (Fox and McSweeney, 1996). Its enzymatic reactions result in desired and undesired effects on dairy products. Plasmin plays a positive role in cheese ripening for many varieties of cheeses (i.e., Emmental, Romano, Swiss, and Gouda); however, its enzymatic action during milk clotting and storage of UHT milk can affect the products adversely.

Plasmin itself is a heat-stable enzyme, which survives pasteurization and many UHT processes (Kennedy and Kelly, 1997). The inhibitors present in fresh milk are heat labile, whereas the activators are known to be heat stable (Richardson, 1983; Lu and Nielsen, 1993). Although several studies describe the kinetics of thermal inactivation of plasmin and/or plasminogen in milk or in model systems (Alichanidis et al., 1986; Rollema and Poll, 1986; Saint Denis et al., 2001) and, more recently, some studies reported the high pressure stability of plasmin (Garcia-Risco et al., 2000, 2003; Scollard et al., 2000), the high-pressure inactivation kinetics of the plasmin system are far less documented.

Taking into account the possible benefits (cheese ripening) and downsides (UHT milk) of plasmin in different applications, it is important to understand its processing stability during high-pressure thermal processing in the context of evaluating the potential of this 
unit operation in dairy applications. Therefore, the aim of this research study was to quantify the inactivation kinetics (thermal and thermal high pressure) of the plasmin system in terms of rate constants and their temperature and pressure sensitivity. Because currently there are no detailed kinetic data available on thermal high-pressure inactivation to reduce the complexity of the real system (milk), we have studied a crude extract as a starting point. Both thermal and high-pressure thermal inactivation were studied on the same system to allow comparison between the 2 unit operations. It is well known that thermal inactivation rate constants (or decimal reduction times) depend largely on the system composition.

\section{MATERIALS AND METHODS}

\section{Isolation of the Plasmin System}

Fresh bovine milk (10 L) was purchased from a local dairy farm. The plasmin system was isolated from milk using the procedure described by Metwalli et al. (1998). The milk was skimmed at $4500 \times g$ for $15 \mathrm{~min}$ at $4^{\circ} \mathrm{C}$, the fat removed, and the defatted milk stored under freezing conditions $\left(-20^{\circ} \mathrm{C}\right)$. Prior to use, the skimmed milk was defrosted and centrifuged at $100,000 \times g$ for $1 \mathrm{~h}$ at $4^{\circ} \mathrm{C}$. The casein pellets were suspended in a milk

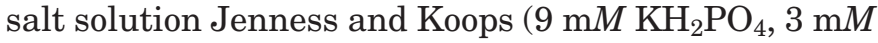
$\mathrm{MgCl}_{2}, 30 \mathrm{~m} M \mathrm{NaCl}, 9 \mathrm{~m} M \mathrm{CaCl}_{2}, 9 \mathrm{~m} M \mathrm{Na}_{3}$ citrate) to the original volume at $\mathrm{pH} 6.6$ and stirred overnight at $4^{\circ} \mathrm{C}$. The $\mathrm{pH}$ of the casein solution was lowered to 2.5 using $\mathrm{H}_{2} \mathrm{SO}_{4}(7 \mathrm{~N})$ followed by a 1-h storage of the samples at room temperature. The precipitate was removed by centrifugation at $14,000 \times g$ for $35 \mathrm{~min}$ at $4^{\circ} \mathrm{C}$. Ammonium sulfate was added to the supernatant containing the plasmin system to a 400 -g/L final concentration and centrifuged at $14,000 \times g$ for $35 \mathrm{~min}$. To improve the separation, the precipitate obtained was washed twice with the Jenness and Koops salt solution buffer (pH 6.6) containing ammonium sulfate $(200 \mathrm{~g} / \mathrm{L}$ final concentration) and centrifuged at $14,000 \times g$ for $35 \mathrm{~min}$.

The final precipitate was suspended in phosphate buffer ( $\mathrm{pH} \mathrm{6.6)}$ to $20 \%$ of the original volume of the supernatant, and $0.02 \% \mathrm{NaN}_{3}$ was added to prevent microbial growth. Using this separation procedure, a partially purified plasmin system could be obtained (Metwalli et al., 1998). These samples were kept at $-80^{\circ} \mathrm{C}$ until use.

\section{Thermal/High-Pressure Treatments}

Prior to the inactivation studies, dilutions 1:3 (vol/ vol) of the plasmin system were prepared in phosphate buffer ( $\mathrm{pH}$ 6.6).
All isothermal inactivation experiments were performed in a thermostatic oil bath at various constant temperatures. The samples were filled in $200-\mu \mathrm{L}$ Blaubrand glass capillaries to obtain "quasi" isothermal conditions. Afterward, the thermal treatment capillaries were cooled in an ice bath and the residual activity was measured.

The first experiment was considered a thermostability screening study, whereby the samples were treated at different temperatures $\left(37\right.$ to $\left.95^{\circ} \mathrm{C}\right)$ for a fixed time interval ( $5 \mathrm{~min}$ ). In these experiments, 2 plasmin containing systems were considered: 1 ) the diluted plasmin system as such and 2) a system whereby, prior to the thermal treatment, plasminogen was converted into plasmin. Two experimental conditions during the conversion were evaluated. In a first step, optimal reaction conditions using a 2 -h incubation at $37^{\circ} \mathrm{C}$ of $100 \mu \mathrm{L}$ of plasmin system and $100 \mu \mathrm{L}$ of urokinase solution (1000 Plough U/mL) in $1200 \mu \mathrm{L}$ of $0.05 M$ Tris-HCl buffer (pH 8.5) were evaluated. In a second step, in order to compare the thermostability results with the unconverted samples, the conversion of plasminogen into plasmin was also studied in a $0.05 M$ phosphate buffer (pH 6.6). Only samples whereby the conversion was carried out according to the latter procedure were used in the thermostability experiments.

Following the screening experiment, a detailed kinetic study (inactivation as a function of temperature and time) to obtain the inactivation rate constants was carried out on the plasmin system containing both plasmin and plasminogen (no conversion).

Isobaric-isothermal (pressure/temperature) treatments were conducted in multivessel (eight 8-mL vessels) high-pressure equipment (Resato, Roden, The Netherlands), allowing a maximal pressure of 1000 MPa. A mixture of oil and glycol (TR15, Resato) was used as the pressure-transmitting fluid. Flexible microtubes $(0.375 \mathrm{~mL}$, Elkay, Leuven, Belgium) were filled with enzyme solution and then submerged in the pressure vessels equilibrated at a certain temperature. To minimize adiabatic heating, pressure was built up slowly, at a constant rate $(100 \mathrm{MPa} / \mathrm{min})$, until the preset pressure was reached, whereupon the valves of the individual vessels were closed and the central circuit was decompressed (Van Loey et al., 1998). An additional 2-min equilibration period was taken into account to ensure constant preset temperatures. Subsequently, the first vessel was decompressed and the enzyme activity of this sample was considered to be the reference value $\mathrm{A}_{0}$. The other 7 vessels containing the sample were decompressed as a function of time. After the pressure-temperature treatment, the samples were immediately transferred into ice water and the residual plasmin activity was determined. Plasmin stability was 
studied at pressures from 300 to $700 \mathrm{MPa}$ combined with temperatures of 35 to $65^{\circ} \mathrm{C}$. Please note that this experimental procedure allows (for first-order reaction systems, which was the case here) for the study of the inactivation process (and thus allows one to obtain inactivation rate constants) at constant pressure and temperature, thereby avoiding the dynamic conditions of pressure and temperature due to adiabatic heating.

\section{Plasmin Activity Assay}

After the thermal or high-pressure thermal treatment, the residual plasmin activity of the samples was evaluated according to the method of Richardson (1983). The plasmin activity was measured using $\mathrm{N}$ succinyl-L-alanyl-L-phenylalanyl-L-lysyl-7-amido-4methyl coumarin acetate salt $(1 \mathrm{~m} M)$ dissolved in 26.4 $\mathrm{mL}$ of $0.05 M$ (pH 7.5) Tris-HCl and $6.6 \mathrm{~mL}$ of dimethyl sulfoxide, as a substrate.

The fluorescent intensity of the reaction product formed due to the enzyme activity, namely 7-amino-4methyl coumarin, was measured continuously for 45 min with a fluorescence spectrophotometer (Varian, type Eclipse). The excitation and emission wavelengths were $350 \mathrm{~nm}$ (5-nm excitation slit) and $460 \mathrm{~nm}$ (10-nm emission slit). The temperature during the reaction was maintained at $37^{\circ} \mathrm{C}$ (using an external water bath connected to the spectrofluorometer). The reaction mixture consisted of $1050 \mu \mathrm{L}$ of Tris-HCl buffer $(0.05 M, \mathrm{pH}$ 7.5), $125 \mu \mathrm{L}$ of sample, and $200 \mu \mathrm{L}$ of coumarin peptide. The enzymatic activity was determined as the slope of the plot of absorbance vs. reaction time.

\section{Data Analysis}

In case of extrinsic/intrinsic factors being constant as a function of time, and if first-order kinetics applies, the thermal inactivation of enzymes can be described as (Ludikhuyze et al., 2002; Weemaes et al., 1998):

$$
\ln \frac{A}{A_{0}}=-k_{o b s} t
$$

where $\mathrm{A}_{0}$ is the initial activity (at $\mathrm{t}=0$ ) and $\mathrm{A}$ is the residual activity at time $t$, after the treatment.

For each pressure-temperature combination, the inactivation rate constant for thermal inactivation of plasmin was estimated by applying a linear regression approach.

Next to the inactivation rate constant, the decimal reduction time (D) can be used to characterize the inactivation process. The relation between the decimal reduction time and the inactivation rate constant is given by equation [2]:

$$
D=2.303 / k
$$

The temperature dependency (at constant pressure) of the rate constant and the decimal reduction time can be characterized by the activation energy (based on the Arrhenius equation [3]) and the $\mathrm{z}_{\mathrm{T}}$-value (thermal death time equation [4]), respectively:

$$
\begin{gathered}
\ln k_{o b s}=\ln k_{r e f}-\left[\frac{E_{a}}{R}\left(\frac{1}{T}-\frac{1}{T_{r e f}}\right)\right] \\
\log _{10}(D)=\log _{10}\left(D_{r e f}\right)-\left(\left(T-T_{r e f}\right) / z_{T}\right)
\end{gathered}
$$

where $\mathrm{k}_{\text {ref }}$ is the rate constant at reference temperature $\mathrm{T}_{\text {ref }}, \mathrm{E}_{\mathrm{a}}$ is the activation energy, $\mathrm{R}$ is the universal gas constant $(\mathrm{R}=8314 \mathrm{~J} / \mathrm{mol} \mathrm{K}), \mathrm{D}_{\text {ref }}$ is the decimal reduction time at reference temperature, and $z_{T}$ is the $z$ value (temperature that results in a 10 -fold reduction in decimal reduction time). The activation energy and z-value were estimated using a linear regression analysis.

The thermal inactivation data were analyzed according to both the Arrhenius equation and the thermal death time model (to compare our data with existing literature data); the high-pressure thermal inactivation data were analyzed according to the Arrhenius approach.

The pressure dependency of a rate constant (at constant temperature) is commonly described by the Eyring equation [5]:

$$
\ln k_{\text {obs }}=\ln k_{r e f}-\left[\frac{V_{a}}{R T}\left(P-P_{r e f}\right)\right]
$$

where $\mathrm{k}_{\mathrm{ref}}$ is the rate constant at reference pressure $\mathrm{P}_{\text {ref, }}, \mathrm{Va}$ is the activation volume, $\mathrm{T}$ is the absolute temperature, and $\mathrm{R}$ is the universal gas constant.

\section{RESULTS AND DISCUSSION}

\section{Isolation Procedure and Activity Assays}

Isolation and partial purification were achieved through ultracentrifugation because it has been shown that this method generally results in higher plasmin activity compared with isoelectric precipitation (Nielsen, 2002). Compared with the method described by Metwalli et al. (1998), 2 complementary steps of washing with ammonium sulfate were introduced to improve the separation of the plasmin system. In addition, the whole separation process was carried out at $4^{\circ} \mathrm{C}$ to prevent microbial growth and to avoid any increase in plasmin activity during the separation (Bastian and Brown, 1996). 


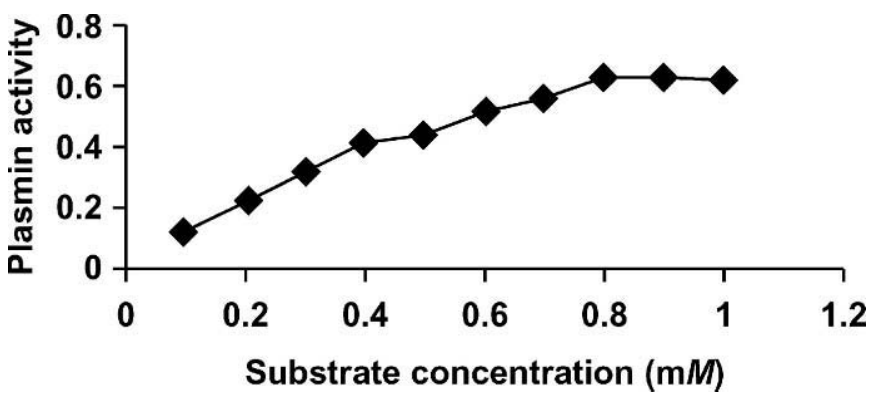

Figure 1. Optimization of the substrate concentration $(1 \mathrm{mM} \mathrm{N}$ succinyl-L-alanyl-L-phenylalanyl-L-lysyl-7-amido-4-methyl coumarin acetate salt dissolved in $26.4 \mathrm{~mL}$ of $0.05 \mathrm{M}$ in $\mathrm{pH} 7.5$ Tris- $\mathrm{HCl}$ and $6.6 \mathrm{~mL}$ dimethyl sulfoxide) to measure plasmin activity.

The activity assay of Richardson (1983) was optimized to ensure that the substrate concentration was substantially higher than the Michaelis-Menten constant, and competitive inhibition by the coumarin peptide was avoided. The substrate concentration vs. relative enzyme activity data (Figure 1 ) shows that a $1 \mathrm{mM}$ substrate concentration satisfies these conditions.

\section{Thermal Inactivation Kinetics of Plasmin}

In a first experiment, the thermal inactivation of the plasmin system containing both plasminogen and plasmin was studied. Plasmin inactivation was investigated in a temperature range of 37 to $97^{\circ} \mathrm{C}$, with a treatment time of $5 \mathrm{~min}$. The results clearly show that inactivation started at approximately $64^{\circ} \mathrm{C}$, and complete inactivation was obtained at $85^{\circ} \mathrm{C}$ (Figure 2). We also observed an increase in activity at temperatures between 50 to $64^{\circ} \mathrm{C}$, with a maximum of a $78 \%$ increase in activity at $61^{\circ} \mathrm{C}$ (compared with the lowest value obtained at around $50^{\circ} \mathrm{C}$ ). This increase in activity has previously

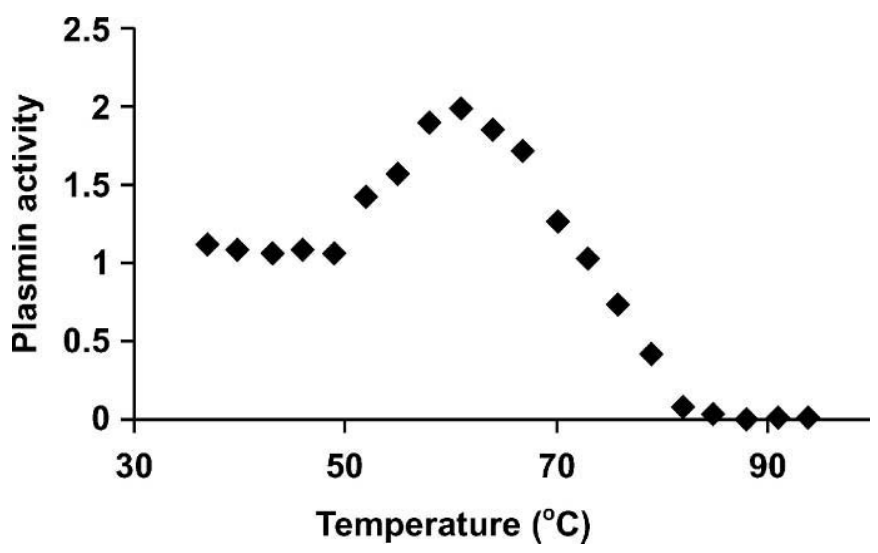

Figure 2. Plasmin activity after $5 \mathrm{~min}$ of isothermal treatment in phosphate buffer ( $\mathrm{pH} 6.6)$.

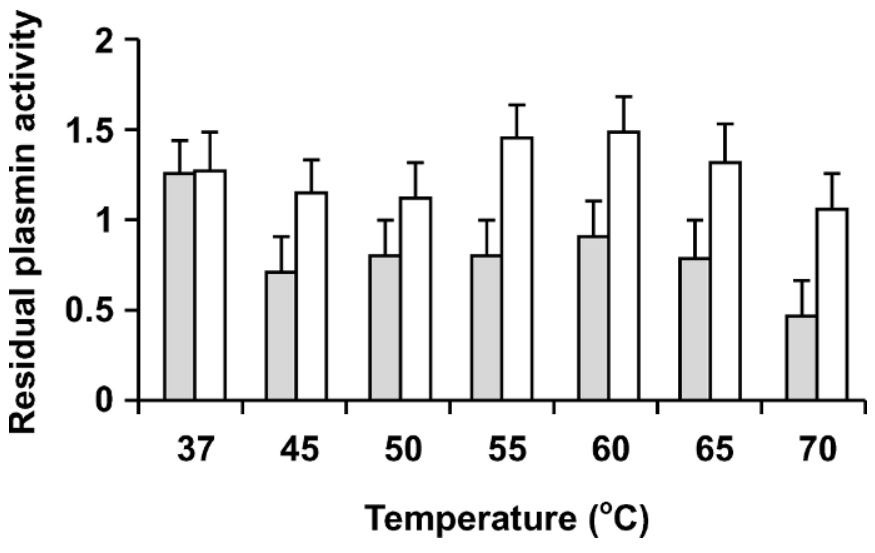

Figure 3. Plasmin thermostability (5-min heating) after conversion of plasminogen into plasmin, in 2 different buffers: $\square$ Tris $\mathrm{HCl}$ ( $\mathrm{pH} 8.5)$ and $\mathrm{phosphate}(\mathrm{pH} 6.6)$.

been reported by other researchers (Richardson, 1983; Fox and McSweeney, 1996) in pasteurized milk, whereas Rollema and Poll (1986) and Saint Denis et al. (2001) reported no increase in plasmin activity at 60 and $70^{\circ} \mathrm{C}$. It was stated that inactivation of inhibitors (Richardson and Pearce, 1981; Fox and McSweeney, 1996) is responsible for the plasmin activity increase in the 50 to $70^{\circ} \mathrm{C}$ temperature range. Our results are in line with this hypothesis and confirm that the plasmin system obtained by ultracentrifugation presumably contains some of the inhibitors, in contrast with the study of Saint Denis et al. (2001), who did not report any increase in plasmin activity.

In a second series of experiments, the thermal stability of plasmin was studied in the same way after converting plasminogen into plasmin with urokinase. The conversion of plasminogen into plasmin resulted in a 3.5 -fold increase in plasmin activity, which is in agreement with previously reported values (Nielsen, 2003). This increase was obtained both when the optimal conditions for converting plasminogen into plasmin (0.05 $M$ Tris-HCl buffer $\mathrm{pH} 8.5$ at $37^{\circ} \mathrm{C} / 1 \mathrm{~h}$ ) were applied, as well as when the conversion took place in 0.05 $M$ phosphate buffer ( $\mathrm{pH} 6.6$ ) at $37^{\circ} \mathrm{C} / 1 \mathrm{~h}$. After a 5 -min thermal treatment at different temperatures, the activity increase was significant: $30 \%$ under optimal conditions, and 25\% when phosphate buffer was used (compared with the lowest value observed at approximately $50^{\circ} \mathrm{C}$ ). These data confirm the hypothesis that a thermolabile plasmin inhibitor is present in the plasmin system under study, since the increase in plasmin activity could be also noticed in the system without plasminogen (Figure 3).

In a third series of experiments, we studied the thermal inactivation kinetics of the original plasmin system (no conversion of plasminogen into plasmin). Detailed 


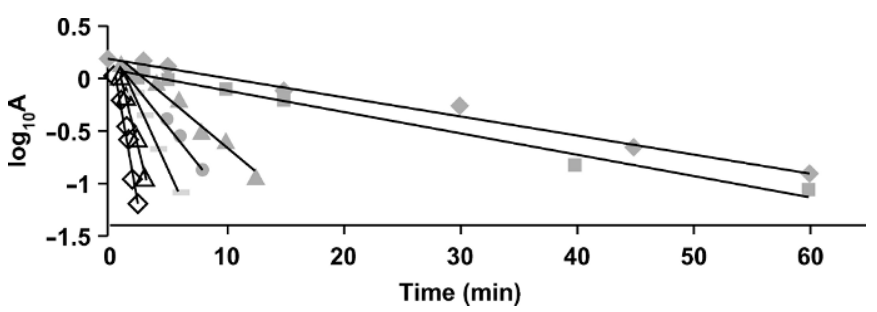

Figure 4. Thermal inactivation kinetics of the plasmin system in phosphate buffer $(\mathrm{pH} 6.6)$ at temperatures between 72.5 to $90^{\circ} \mathrm{C}: 72.5$ $(\diamond) ; 75(\mathbf{\square}) ; 80(\Delta) ; 82(\bullet) ; 85(-) ; 87(\triangle) ; 90^{\circ} \mathrm{C}(\diamond)$.

thermal inactivation kinetics of the plasmin system were studied at temperatures between 72.5 and $90^{\circ} \mathrm{C}$. The applicability of the first-order kinetic model, which is frequently reported in the literature (Alichanidis et al., 1986; Rollema and Poll, 1986; Saint Denis et al., 2001) to describe plasmin or plasminogen inactivation, was confirmed for the plasmin system under study (Figure 4). Inactivation rate constants and decimal reduction time values were estimated by linear regression analysis and are presented in Table 1. As expected, decimal reduction time decreases with temperature increase. Table 2 compares our data with data previously obtained by other researchers. Rollema and Poll (1986) studied the plasmin thermal inactivation kinetics in skim milk and in different media (i.e., in Jenness and Koops salt). Our data are consistent with their results; the inactivation rate constants we obtained are between the values reported by Rollema and Poll (1986) for plasmin inactivation in Jenness and Koops salt and in skim milk. Alichanidis et al. (1986) studied kinetics of thermal inactivation of plasmin in a system isolated from milk by isoelectric precipitation and added exogenous porcine plasmin in phosphate buffer. The inactivation rate constants reported by Alichanidis et al. (1986) are higher than the ones found in this study. Saint Denis et al. (2001) studied plasmin activity without whey proteins in a system separated from milk by isoelectric precipitation and/or added exogenous plasmin to UHT milk. The inactivation rate constants reported by these authors are almost 2-fold higher than those reported in our research at 80 and $85^{\circ} \mathrm{C}$, and much higher at lower temperatures. The differences in the inactivation rate constant between our study and others mentioned in Table 2 might be attributed to differences in the system composition resulting from the isolation method, the buffers used, and the $\mathrm{pH}$ values investigated.

To express the temperature dependence of the inactivation rate constant, the Arrhenius equation [6] was used and an activation energy of $226.86 \mathrm{~kJ} / \mathrm{mol}$ (Figure 5 ) was obtained. This value is in agreement with the previous values reported by Saint Denis et al. (2001) of $244 \mathrm{~kJ} / \mathrm{mol}$ for plasmin and $230 \mathrm{~kJ} / \mathrm{mol}$ for plasminogen in the 70 to $90^{\circ} \mathrm{C}$ temperature range, and is close to the value determined by Alichanidis et al. (1986) of $170 \mathrm{~kJ} / \mathrm{mol}$ in the 72 to $85^{\circ} \mathrm{C}$ temperature range. However, these activation energies are much higher than the value of $52.75 \mathrm{~kJ} / \mathrm{mol}$ found by Kennedy and Kelly (1997) for plasmin inactivation in the temperature range of 63 to $110^{\circ} \mathrm{C}$ in milk with low SCC.

It is clear that one must consider the different environmental conditions that can affect system stability, including factors such as the presence of casein, which has a protective effect on plasmin, and $\beta$-lactoglobulin, which can accelerate plasmin inactivation (Nielsen, 2002), when analyzing the differences in rate constants/ decimal reduction times and activation energies/z-values (temperature that results in a 10 -fold reduction in decimal reduction time) reported in the literature.

\section{Pressure Stability at Room Temperature}

Screening experiments revealed that when the plasmin system is subjected to high pressure (100 to 800 $\mathrm{MPa}$ ) for $60 \mathrm{~min}$ at room temperature, the system exhibits pressure stability (Figure 6). This is in agreement with previous studies (Scollard et al., 2000; Huppertz et al., 2002, Garcia-Risco et al., 2003), which indicate that plasmin at room temperature, in phosphate buffer

Table 1. Rate constants and decimal reduction times (D-values) for thermal inactivation of the plasmin system.

\begin{tabular}{llc}
\hline $\begin{array}{l}\text { Temperature } \\
\left({ }^{\circ} \mathrm{C}\right)\end{array}$ & $\begin{array}{l}\mathrm{k} \times 10^{-2} \\
\left(\mathrm{~min}^{-1}\right)\end{array}$ & $\begin{array}{l}\text { D-values } \\
(\mathrm{min})\end{array}$ \\
\hline 72.5 & $4.29 \pm 0.0024^{\mathrm{a}}(0.98)$ & $54.58 \pm 2.66(0.98)$ \\
75 & $4.60 \pm 0.0035(0.97)$ & $49.12 \pm 3.72(0.97)$ \\
80 & $21.58 \pm 0.0125(0.98)$ & $10.60 \pm 0.61(0.98)$ \\
82 & $32.23 \pm 0.0177(0.98)$ & $7.145 \pm 0.39(0.98)$ \\
85 & $53.5 \pm 0.0239(0.98)$ & $4.30 \pm 0.19(0.99)$ \\
87 & $108.4 \pm 0.128(0.96)$ & $2.12 \pm 0.25(0.96)$ \\
90 & $139.3 \pm 0.201(0.94)$ & $1.59 \pm 0.148(0.97)$ \\
& $\mathrm{Ea}=226.86 \mathrm{~kJ} / \mathrm{mol} \pm 14^{\mathrm{a}}(0.98)$ & $\mathrm{z}_{\mathrm{T}}=10.48 \pm 0.63^{\mathrm{a}}(0.98){ }^{\circ} \mathrm{C}$ \\
\hline
\end{tabular}

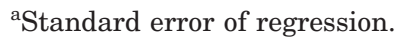


Table 2. Comparative thermal kinetics results for plasmin activity.

\begin{tabular}{|c|c|c|c|c|c|}
\hline \multirow[b]{3}{*}{$\begin{array}{l}\text { Temperature } \\
\left({ }^{\circ} \mathrm{C}\right)\end{array}$} & \multicolumn{5}{|c|}{ Reference/enzyme } \\
\hline & \multicolumn{2}{|c|}{$\begin{array}{l}\text { Rollema and Poll } \\
\text { (1986) }\end{array}$} & \multirow{2}{*}{$\begin{array}{l}\text { Alichanidis et al. } \\
\qquad(1986) \\
\text { Porcine } \\
\text { plasmin in } \\
\text { phosphate } \\
\text { buffer }\end{array}$} & \multirow{2}{*}{$\begin{array}{l}\text { Saint Denis et al. } \\
\qquad(2001)\end{array}$} & \multirow{2}{*}{$\begin{array}{l}\text { This study } \\
\text { Plasmin } \\
\text { system in } \\
\text { phosphate } \\
\text { buffer }\end{array}$} \\
\hline & $\begin{array}{l}\text { Plasmin } \\
\text { system } \\
\text { in milk }\end{array}$ & $\begin{array}{l}\text { Plasmin } \\
\text { system in } \\
\text { Jenness and } \\
\text { Koops salt }\end{array}$ & & & \\
\hline & & & $\mathrm{k} \times 10^{-2}(\mathrm{mi}$ & & \\
\hline 70 & 12.6 & - & - & 1.18 & - \\
\hline 72.5 & - & - & 18.57 & - & 4.29 \\
\hline 75 & 41.4 & - & - & 20.94 & 4.60 \\
\hline 80 & 84 & 4.62 & - & 73.89 & 21.58 \\
\hline 85 & 150 & 7.8 & 115.15 & 109.67 & 53.5 \\
\hline
\end{tabular}

in the presence or absence of sodium caseinate, was barostable up to $600 \mathrm{MPa}$, but was significantly inactivated at $400 \mathrm{MPa}$ in the presence of $\beta$-lactoglobulin.

After $1 \mathrm{~h}$ of high-pressure treatment, a slight but nonsignificant decrease in plasmin activity was observed at $500 \mathrm{MPa}$, and for pressures higher than 600 $\mathrm{MPa}$, an increase in the residual plasmin activity compared with $500 \mathrm{MPa}$ is observed, indicating an increased stability at pressures $\geq 600 \mathrm{MPa}$.

\section{Combined Pressure and Temperature Inactivation}

Detailed high-pressure thermal inactivation kinetics were conducted in the pressure range of 100 to $800 \mathrm{MPa}$ and between 30 and $65^{\circ} \mathrm{C}$.

High-pressure treatments combined with temperatures exceeding $30^{\circ} \mathrm{C}$ clearly resulted in plasmin inactivation. Linear curves were obtained when the residual plasmin activity was plotted as a function of time on a

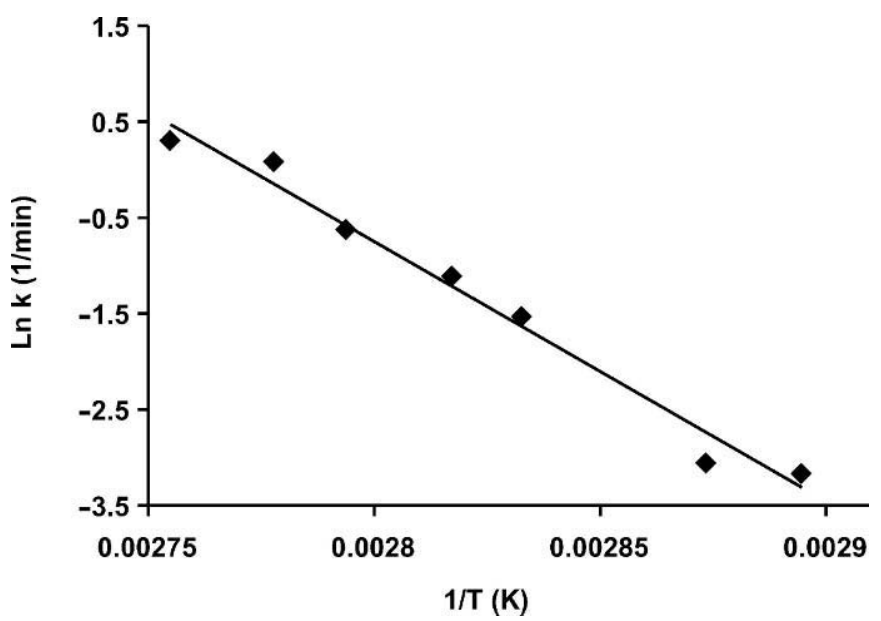

Figure 5. Arrhenius plot for thermal inactivation of plasmin system between 72.5 to $90^{\circ} \mathrm{C}$. log linear scale, indicating first-order kinetics (as observed for thermal inactivation). Using linear regression, the corresponding $k$-values were estimated (Table 3). From Table 3, a synergistic effect of temperature and pressure between 300 to $600 \mathrm{MPa}$ can be observed. At constant pressure, an increase in k-values with increasing temperature is observed. At constant temperature, an increase in inactivation rate constant with increasing pressure is observed for pressures between 300 and $600 \mathrm{MPa}$. Above $600 \mathrm{MPa}$, at constant temperature, an antagonistic effect followed by a stabilization effect is observed, characterized by a decrease in inactivation rate constant followed by a stabilization of the inactivation rate constant. An antagonistic effect of pressure and temperature is frequently encountered for enzyme inactivation in the lower range of pressures $(<100 \mathrm{MPa})$ (Heremans, 2002), and seldom in the pressure range above $200 \mathrm{MPa}$.

Although pressure stabilization against temperature inactivation at elevated pressures is a less encountered phenomenon, this might be related to the disruption of thiol-disulfide bonds and interactions between the

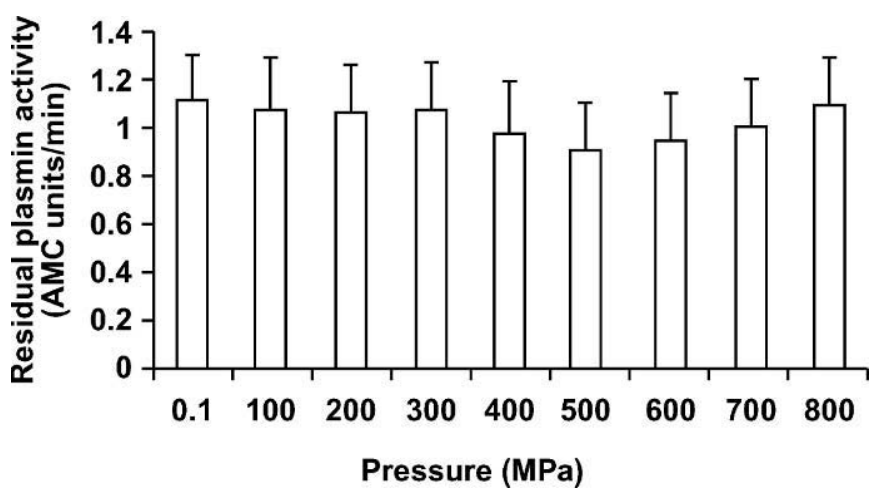

Figure 6. Pressure stability of the plasmin system at room temperature within a 60 -min pressurization time. 


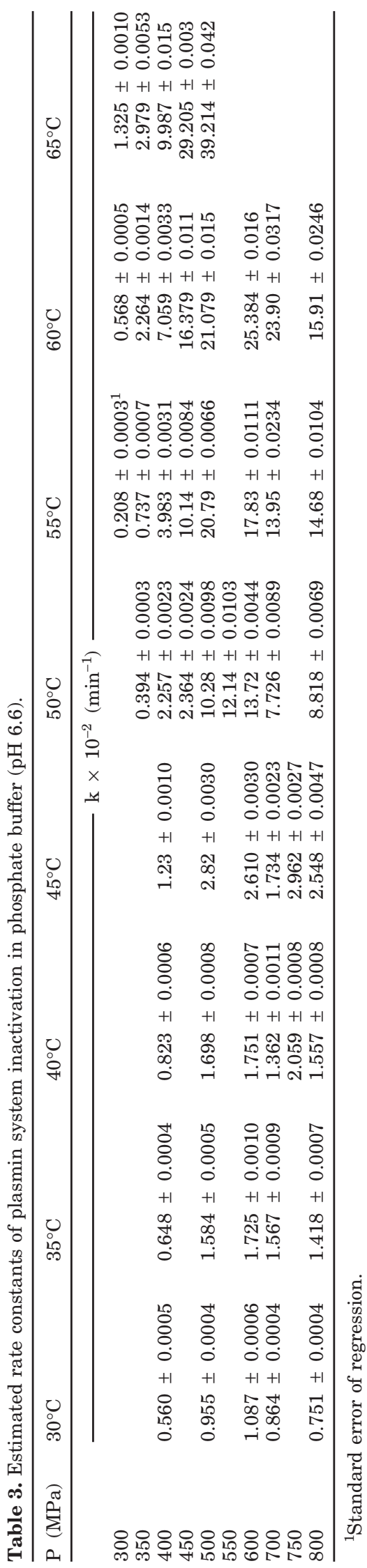

Table 4. Activation energies (Ea) for pressure-temperature inactivation of the plasmin system.

\begin{tabular}{lc}
\hline $\mathrm{P}(\mathrm{MPa})$ & $\mathrm{Ea}(\mathrm{kJ} / \mathrm{mol})$ \\
\hline 300 & $170.73 \pm 6.90^{1}(0.99)$ \\
350 & $130.72 \pm 19.4(0.96)$ \\
400 & $75.03 \pm 6.02(0.96)$ \\
450 & $146.09 \pm 27.49(0.93)$ \\
500 & $96.70 \pm 9.03(0.95)$ \\
600 & $96.63 \pm 13.85(0.91)$ \\
700 & $95.703 \pm 14.87(0.89)$ \\
800 & $93.18 \pm 9.99(0.95)$ \\
\hline
\end{tabular}

${ }^{1}$ Standard error of regression.

subunits formed. The structure of plasminogen is stabilized by 3 disulfide bonds in each of the 5 kringles, whereas the plasmin structure is a 2-chain molecule, namely a heavy chain and a light chain, stabilized by one disulfide bridge (Bastian and Brown, 1996). This structure might be disrupted by a high-pressure thermal treatment, which can favor reassociation between the plasmin and plasminogen subunits. This hypothesis requires further confirmation.

At all pressure levels studied, the increase in the inactivation rate constant with temperature at constant pressure can be expressed by the Arrhenius equation. The activation energies were estimated using linear regression and are summarized in Table 4. From this table, it can be seen that the activation energy changes with pressure. In general, at elevated pressures, the activation energy decreases compared with atmospheric pressure, which indicates that the inactivation rate constant is less temperature sensitive at elevated pressures. Due to the phenomena observed above 600 $\mathrm{MPa}$, the relationship between the inactivation rate constant (k) and pressure cannot be described by the Eyring equation [7].

\section{CONCLUSIONS}

The thermal stability of a plasmin system obtained by ultracentrifugation and containing both plasminogen and plasmin in phosphate buffer was studied in detail. In a temperature range of 50 to $64^{\circ} \mathrm{C}$, an increase in plasmin activity is observed that might be attributed to the inactivation of plasmin inhibitors. At higher temperatures, the system shows first-order inactivation kinetics. The activation energy and inactivation rate constants were estimated for thermal inactivation of the plasmin system in phosphate buffer at $\mathrm{pH}$ 6.6. The value of the activation energy for the thermal treatment is in line with previously reported values for plasmin inactivation in model systems and in milk.

The plasmin system is very pressure stable at room temperature. A synergistic effect of high pressure and 
temperature is observed in the 300 to $600 \mathrm{MPa}$ and 35 to $65^{\circ} \mathrm{C}$ ranges, and a stabilization effect could be observed for pressures above $600 \mathrm{MPa}$. In depth studies on the structural changes and disulfide bond cleavage inside plasmin during combined high-pressure thermal treatments for the same system, converting plasminogen to plasmin with urokinase would be interesting to pursue to mechanistically understand this phenomenon. This approach could allow one to gain insight into the unfolding and refolding of the subunits formed. The temperature dependence of the inactivation rate constant of the plasmin system at elevated pressure could be successfully described by the Arrhenius equation. Further studies are required to formulate an appropriate global mathematical model for the plasmin system inactivation. Further studies are required to evaluate the applicability of high-pressure thermal processes in cheese making or other dairy products. Particular attention could be given to the stability of the plasmin system at pressures above $600 \mathrm{MPa}$ and the possibilities of high-pressure thermal inactivation of plasmin in the 300 - to $600-\mathrm{MPa}$ and 36 to $65^{\circ} \mathrm{C}$ range.

\section{ACKNOWLEDGMENTS}

The authors wish to thank the European Commission (QLK1-CT-2000-60014) and the Fund for Scientific Research-Flanders (FWO) for their financial support

\section{REFERENCES}

Alichanidis, E., J. H. M. Wrathall, and A. T. Andrews. 1986. Heat stability of plasmin (milk proteinase) and plasminogen. J. Dairy Res. 53:259-269.

Bastian, E. D., and R. J. Brown. 1996. Plasmin in milk and dairy products: An update. Int. Dairy J. 6:435-457.

Crudden, A., and A. L. Kelly. 2003. Studies of plasmin activity in whey. Int. Dairy J. 12:987-993.

Fox, P. F., and P. L. H. McSweeney. 1996. Proteolysis in cheese. Food Rev. Int. 12:457-509.

Garcia-Risco, M. R., A. Olano, M. Ramos, and R. Lopez-Fandino. 2000. Micelar changes induced by high pressure. Influence in the proteolytic activity and organoleptic properties of milk. J. Dairy Sci. 83:2184-2189.
Garcia-Risco, M. R., I. Recio, E. Molina, and R. Lopez-Fandino. 2003. Plasmin activity in pressurized milk. J. Dairy Sci. 86:728-734.

Grufferty, M. B., and P. F. Fox. 1986. Potassium iodate-induced proteolysis in ultra high heat treated milk during storage: the role of $\beta$-lactoglobulin and plasmin. J. Dairy Res. 53:139-177.

Heremans, K. 2002. The effects of high pressure in biomaterials. Pages $22-46$ in Ultra High Pressure Treatments. M. Hendrickx and D. Knorr, ed. Kluwer Academic/Plenum Publishers, New York.

Huppertz, T., A. Kelly, and P. F. Fox. 2002. Effects of high pressure and properties of milk. Int. Dairy J. 12:561-633.

Kennedy, A., and A. L. Kelly. 1997. The influence of somatic cell count on the heat stability of bovine milk plasmin activity. Int. Dairy J. 7:717-721.

Lu, D. D., and S. Nielsen. 1993. Heat inactivation of native plasminogen activators in bovine milk. J. Food Sci. 58:1010-1016.

Ludikhuyze, L., A. Van Loey, Indrawati, S. Denys, and M. Hendrickx. 2002. Effects of high pressure on enzymes related to food quality. Pages 115-160 in Ultra High Pressure Treatments. M. Hendrickx, D. Knorr, ed. Kluwer Academic/Plenum Publishers, New York.

Metwalli, A. M., H. H. de Jongh, and M. A. J. S. van Boekel. 1998. Heat inactivation of bovine plasmin. Int. Dairy J. 8:47-56.

Nielsen, S. S. 2002. Plasmin system and microbial proteases in milk: Characteristics, roles, and relationship. J. Agric. Food Chem. 50:6628-6634.

Nielsen, S. S. 2003. Plasmin system in milk. Pages 929-934 in Encyclopedia of Dairy Sciences. Vol II. H Roginskin, J. W. Fuquay, P. F. Fox, ed. Academic Press, London, UK.

Preceti, A. S., M. P. Oria, and S. S. Nielsen. 1997. Presence in bovine milk of two protease inhibitors of the plasmin system. J. Dairy Sci. 80:1490-1496.

Richardson, B. C. 1983. The proteinases of bovine milk and the effect of pasteurization on their activity. N. Z. J. Dairy Sci. Technol. 18:223-245.

Richardson, B. C., and K. N. Pearce. 1981. The determination of plasmin in dairy products. N. Z. J. Dairy Sci. Technol. 16:209-220.

Rollema, H. S., and J. K. Poll. 1986. The alkaline milk proteinase system: Kinetics and mechanism of heat inactivation. Milchwissenschaft 41:536-540.

Saint Denis, T., G. Humbert, and J. L. Galliard. 2001. Heat inactivation of native plasmin, plasminogen and plasminogen activators in bovine milk: A revisited study. Lait 81:715-729.

Scollard, P. G., T. P. Beresford, P. M. Murphy, and A. L. Kelly. 2000. Barostability of milk plasmin activity. Lait 80:609-619.

Van Loey, A., C. Weemaes, I. Van den Broeck, L. Ludikhuyze, Indrawati, S. Denys, and M. Hendrickx. 1998. Thermal and pressuretemperature degradation of chlorophill in broccoli juice: A kinetic study. J. Agric. Food Chem. 46:5289-5294.

Weber, B. A., and S. S. Nielsen. 1991. Isolation and partial characterization of a native serine-type protease inhibitor from bovine milk. J. Dairy Sci. 74:764-771.

Weemaes, C., L. Ludikhuyze, I. Van den Broeck, and M. Hendrickx. 1998. Kinetics of combined pressure-temperature inactivation of avocado polyphenoloxidase. Biotechnol. Bioeng. 60:292-299. 